\title{
Are Shocks to Petroleum Products Consumption Permanent or Temporary: A New Evidence from LM Unit Root Tests with Structural Breaks
}

\author{
Sameh A. Ajlouni ${ }^{1 *}$, Abdallah M. Ghazo ${ }^{2}$, Ziad M. Abu-Lila ${ }^{2}$ \\ ${ }^{l}$ Department of Economics, Faculty of Economics and Administrative Sciences, Yarmouk Univeristy, Irbid, Jordan \\ ${ }^{2}$ Department of Economics of Finance and Business, Faculty of Economics and Administrative Sciences, Al-Albayt University, Mafraq, Jordan
}

\begin{abstract}
The purpose of this paper is to examine whether shocks to the consumption of petroleum products in Jordan have permanent or temporary effects. This has been accomplished by applying Lee and Strazicich (2003) test of unit root with structural breaks to investigate the stationarity properties related to the time series of petroleum products consumption over the period 1961 to 2019 . Empirical findings lend evidence that the consumption of petroleum products is a unit root process, implying that shocks to petroleum products consumption has permanent impact, and this consumption does not turn back to its time trend path following a shock. This indicates that there are high possibilities of energy demand management and conservation policies targeted towards achieving the intended goals in the long-run. In fact, this is compatible with the government energy strategies aimed at reducing the consumption of fossil oils.
\end{abstract}

\section{Keywords:}

Petroleum Products; Jordan; Unit Root;

Stationarity; Structural Breaks.

\section{Article History:}

Received: $\quad 10 \quad$ February 2021

Revised: $\quad 26$ April 2021

Accepted: 08 May 2021

Published: 01 June 2021

\section{1- Introduction}

Testing the stationarity of energy consumption variables has become a common practice in the literature of energy economics. It is also critical for researchers and policymakers alike. Knowing whether energy consumption is stationary or not (i.e., has a unit root) is both crucial for the effectiveness of energy conservation and the policies of demand management [1]. Worldwide, voluminous research was devoted to investigating stationarity properties related to the variables of diverse energy consumption (e.g. oil consumption, energy consumption per capita, renewable energy consumption, consumption of non-fossil energy, coal consumption, natural gas consumption, per capita electricity consumption, petroleum consumption, etc.). However, little research of this kind was conducted for Arab countries in general and for Jordan in particular. Jordan is a developing Arab non-oil producing country that lies in the MENA region. Moreover, it heavily relies on importing energy products including oil, which is refined domestically into diverse petroleum products ${ }^{\dagger}$. The high reliance on oil imports has exerted excessive pressures on the government's budget due to the high import bills coupled with the heavy levels of fuel subsidies provided by the government. Faced with growing fiscal constraints, national energy strategies were developed to attain several goals including reducing fossil fuels consumption. To attain this goal, several measures and policies were designed. Nonetheless, the impact of these measures and policies could be transitory or permanent depending on whether oil consumption is a unit root process or

* CONTACT: Ajlouni.sameh@yu.edu.jo

DOI: http://dx.doi.org/10.28991/esj-2021-01279

(C) 2021 by the authors. Licensee ESJ, Italy. This is an open access article under the terms and conditions of the Creative Commons Attribution (CC-BY) license (https://creativecommons.org/licenses/by/4.0/).

$\dagger$ If the demand for petroleum products exceeds the quantities refined domestically, the shortage is met through imports. 
not (i.e., stationary process). In view of this, it is important to employ unit root tests to determine which impact is likely to occur [2]. Admittedly, some research has investigated the stationarity of a number of energy variables in Jordan, being a country within panels of other countries $[3,4]$. However, the literature has hitherto been void of research dedicated to Jordan as a single country per se. Therefore, this study attempts to fill in this gap in the literature and to pioneer a new strand of research for Jordan. This essentially aligns with the recommendations of Smyth \& Narayan (2015), Smyth (2013) and Lean \& Smyth (2013) [5-7] which seek to conduct research in countries other than the United States in order to enrich their knowledge of unit root properties of energy variables. Smyth and Narayan (2015) [5] argue that most single-country studies are US-studies. Furthermore, a lot of knowledge has been accumulated about unit root behavior of energy variables there so far, but this knowledge is notably limited for other countries [7,8].

In particular, this study analyses the stationarity properties of petroleum products consumption series. The motivation to study petroleum products consumption can be justified on several grounds. First, petroleum products consumption constitutes the largest proportion of primary energy consumed in Jordan. Second, petroleum products are vital in nearly all aspects of life including transportation, heating, electricity generation, asphalt production, chemicals, plastics and synthetic materials [1]. Finally, the recent regulatory reforms of the Jordanian market of petroleum products, coupled with the new pricing regime, increases the significance of this research (for a historical overview and market restructuring, see [9]).

It can be argued that the findings of this research can be used to evaluate the effectiveness of the measures which have been employed so far by the Jordanian government to reduce the consumption of fossil oils. Moreover, this research intends to establish a benchmark against which future research can be compared with. It also intends to pave the way for more research aimed at testing the stationarity of other energy variables in Jordan.

Understanding the stationarity properties of petroleum products consumption has several forecasting and policy implications. If consumption is stationary, shocks, such as fuel economy standards, tariffs on imported fuels and vehicles and carbon tax on transportation fuels, will only have temporary effects. In addition, consumption will return to its time trend. However, if consumption has a unit root (i.e., is non-stationary), such shocks will have permanent effects, and consumption will not revert to its time trend [1]. In turn, knowledge of stationarity can guide policy makers to design policies of proper energy conservation and demand management in order to reduce the consumption of fossil fuels as well as to adopt measures that reduce the emissions of $\mathrm{CO}_{2}$ gases. On a related note, if other sectors in the economy are closely associated with the energy sector, permanent shocks to energy sector will have strong effects on these sectors. On another front, if petroleum products consumption proves to be stationary process, then it is possible to forecast future levels of consumption with great accuracy. However, if consumption series has a unit root, forecasting cannot be accurate.

Traditionally, stationarity is tested using a variety of stationarity tests and unit root tests with and without structural breaks. The KPSS test developed by Kwiatkowski (1992) [10] is one of the famous tests of stationarity, whereas the well-known Dickey and Fuller (1979) [11] test is viewed as one of the most famous unit root tests without breaks. This test was later criticized, by Perron (1989) [12], to have low power, i.e., it is biased towards the non-rejection of the false unit root null hypothesis when structural breaks are ignored. To overcome this shortcoming, a variety of methods were developed including the Lee and Strazicich (2003) [13] test for unit root with structural breaks*. This study uses this test to examine the stationarity properties of petroleum products consumption in Jordan. Hopefully, empirical findings can provide some guidelines for the formulation of energy and environmental policies in Jordan, especially the policies aimed at rationalizing the consumption of the highly pollutant fossil fuels. The subsequent part of the current paper is organized as follows. Section 2 presents brief literature review. Section 3 introduces methodology and data. Section 4 discusses results, and Section 5 concludes the research and presents some policy implications.

\section{2- Literature Review}

Narayan and Smyth (2007) [14] pioneered a new line of research in the literature of energy economics that focuses on testing the unit root hypothesis of energy variables $[15,16]$. Following [14], it has become a common practice in the literature to examine the stationarity of energy variables. In a literature survey, [6] cites various studies that tested the unit root hypothesis of energy consumption and energy production variables both within a single country setting and in panels of countries. Some of these studies used univariate unit root tests with and without structural breaks. Some used univariate non-linear unit root tests, whereas others used univariate fractional integration tests. Furthermore, another group of studies used panel unit root tests. The single country studies used a variety of unit root tests such as Augmented Dickey-Fuller (ADF), Phillips-Perron (PP) and Elliott et al. tests. Concerning the existence of unit root, the findings of these studies were mixed. The majority of the studies that employed univariate unit root tests without structural breaks found that energy variables contained unit roots. However, realizing that standard unit root tests, such as ADF and PP, have low power to reject the unit root null hypothesis when the stationary alternative is true under the presence of

\footnotetext{
${ }^{*}$ In the next section we review some of these methods.
} 
structural breaks or nonlinearity in the data generating process casts some doubt on these findings*. To overcome the low power of rejecting a null unit root hypothesis when the alternative is true and structural breaks are ignored, Perron (1989) [12] suggested a modified Dickey-Fuller test that allowed for one exogenous structural break. Later on, Zivot and Andrews (1992) [17], hereafter, they developed a test which was later called the minimum test of ZA. This test allowed for one structural break point that was determined endogenously from the data. As an extension to the ZA test, Lumsdaine and Papell (1997) [18], LP hereafter, proposed a test that allowed for two endogenous structural break points. Lee and Strazicich (2003) [13], LS hereafter, subsequently criticized ZA and LP tests as they assumed no break(s) under the unit root null, implying that the alternative would be "structural breaks are present". Therefore, the alternative could not necessarily imply "trend stationarity with breaks". Rather, it could imply "unit root with breaks". Consequently, the rejection of the null might indicate the rejection of a "unit root without breaks" but not necessarily the rejection of a "unit root" per se. To deal with these shortcomings, Lee and Strazicich [13, 19, 20] developed the minimum Lagrange Multiplier (LM) unit root test with one and two structural breaks as alternatives to the ADF-type tests of ZA and LP. The LS tests allowed for breaks under both the null and the alternative hypotheses. Accordingly, the rejection of the null definitely connotes trend stationarity.

To highlight other flaws inherited in the conventional unit root tests, including the low power to reject the unit root null hypothesis in the presence of non-linearities, as well as under fractional alternative hypothesis, Smyth (2013) [6] reviews some studies that employed non-linear unit root tests and fractional integration tests. Smyth (2013) [6] concludes that most of the studies that employed non-linear unit root tests found evidence of non-stationarity, whereas the majority of the studies that used fractional integration tests reached mixed conclusions regarding the presence of a unit root. Finally, [6] cites some studies that employed panel unit root tests to remedy the short time span and/or structural break problems associated with using univariate unit root tests. Some of these studies employed what is described by Smyth (2013) [6] as the "first generation panel unit root and stationarity tests" with and without structural breaks. In general, the findings of the panel unit root tests without structural breaks were mixed, whereas the findings of the tests that account for structural breaks supported the stationarity hypothesis.

Despite all of these details and irrespective of what test is being used, whether in a setting of a single country or a panel of countries, the purpose of testing for a unit root was primarily intended to investigate whether shocks to energy variables had temporary or permanent effects [14]. As noted by Narayan et al. (2010) [21], testing for the unit root in energy variables is useful in understanding the relative importance of shocks. If the variable does not have a unit root, this means that the impact of a shock is short-term or transitory. Nonetheless, if the variable is non-stationary, the impact of a shock is permanent. Knowing whether shocks are temporary or permanent is useful for forecasting as well as for policymaking. If energy prices prove to be mean reverting, then forecasting future prices is possible. Conversely, if prices follow a random walk, then it is not possible to forecast future prices based on past prices [22, 23]. Likewise, if the series contains unit root, this implies that permanent policy changes will be more effective than temporary policy changes. The converse is expected if the series does not contain unit root [3].

At the empirical level, many studies have tested the unit root properties of diverse energy variables (e.g. oil consumption, energy consumption per capita, renewable energy consumption, consumption of non-fossil energy, coal consumption, natural gas consumption, per capita electricity consumption, petroleum consumption). The majority of the studies carried out the analysis for a panel of countries, whereas a smaller number of studies were devoted to single countries. In particular, we review some of the research concerned with the stationarity of oil consumption, the focus of this study. Apergis and Payne (2010) [1] tested the null hypothesis of a unit root in the petroleum consumption ${ }^{\dagger}$ at the state level of the US from1960 to 2007 . Applying unit root tests, with endogenously determined structural breaks, the null hypothesis of a unit root in petroleum consumption was rejected for most of the states [13, 21]. Solarin and Lean (2016) [2] examined the nonlinear stationarity properties of oil (petroleum) consumption for 57 countries over a 50-year period. They found that the consumption in two thirds of the countries contained a unit root, while the consumption in one third of the countries was stationary. Lean and Smyth (2014) [7] applied the Lagrange multiplier family of unit root tests with structural breaks to examine the stationarity of energy consumption in Malaysia. They specifically analyzed final energy consumption by fuel type ${ }^{\ddagger}$ and final energy demand by sector. In the light of the results, the unit root null could be rejected for 50 percent to 70 percent of disaggregated energy types. At sector level, it was found that policies designed to reduce energy consumption in the industrial and transport sectors would have permanent effects. However, for the residential and commercial sector, the results were unclear. Destek and Sarkodie (2020) [24] examined the stationary properties of coal, oil and natural gas consumption per capita for 16 OECD countries over the period 19702018. Results showed that out of 16 countries, the consumption of coal, oil and natural gas was stationary in six, four and five countries, respectively.

\footnotetext{
* Other limitations of these tests are cited in Smyth (2013).

† Petroleum includes "fuel ethanol blended into motor gasoline".

$\$$ Energy by fuel type includes diesel, fuel oil, motor petrol, LPG, kerosene, ATF and AVG gas, non-energy, natural gas, coal and coke and electricity. The four sectors include industrial, transport, non-energy, and residential and commercial sectors.
} 
Aside from the methodology of Lee and Strazicich (2003) [13], other methods have been employed in the literature to test whether shocks to energy variables are of temporary or permanent nature. For example, Demir and Gozgor (2017) [25] utilized the unit root test of Narayan-Popp with two endogenous (unknown) breaks to test for the existence of a unit root in renewable energy consumption in 54 developed and developing countries over the period 1971-2016. The results were mixed in the sense that in some countries, the consumption of renewable energy had a unit root, whereas in other countries, no evidence of unit root was found.

Akram et al. (2019) [26] employed the two-step Lagrange Multiplier (LM) and the three-step Residual Augmented Least Square Lagrange Multiplier (RALS-LM) unit root tests to examine the stationary properties of electricity consumption at the aggregate and user-group levels for 18 Indian states over the period 1971-2016. Ultimately, they found evidence of stationarity for most of the Indian states.

Aydin and Pata (2020) [27] used wavelet-based unit root test with smooth structural shifts to test whether shocks to disaggregated renewable energy consumption could be permanent or temporary for the USA. As a general conclusion, they discovered that most types of renewable energy consumption had a unit root in the USA.

In a recent study, Lee et al. (2021) [28] employed non-linear quantile unit-root test and Fourier quantile unit-root test to investigate the hysteresis properties and growth stability of total and disaggregated renewable energy productions in the U.S for the period 1973:01 to 2019:08. They found that all renewable energy production series were stationary.

Lee, Ranjbar and Lee (2021b) [29] used quantile unit-root test with smooth breaks to test the persistence of shocks on renewable energy consumption in the USA over the period 1960-2017. Their findings indicated that the unit-root hypothesis was rejected for the renewable energy consumption series for 32 of the 51 states.

As shown above, diverse methods were employed in the literature to test whether shocks to energy variables had permanent or transitory effects. However, the current study chooses to use the LS minimum Lagrange multiplier unit root test method since it has not been previously used in the context of Jordan and, therefore, can be used as a benchmark for future studies that employ other methods.

To reiterate, conclusions concerning stationarity have been mixed necessitating the need to conduct further research to gain additional knowledge and to formulate bases against which future research can be compared to.

\section{3- Methodology and Data}

\section{3-1- LS Minimum Lagrange Multiplier Unit Root Test}

Before proceeding with the LS test, it is worth mentioning that Perron (1989) [12] considered three models. Model A (the crash model) that allows for a one change in level. Model B that allows for one change in trend slope (the changing growth model), and Model $\mathrm{C}$ that allows for a change in both the level and trend. The LS test allows for two endogenous breaks under both the null and alternative hypotheses. The alternative hypothesis of this test unambiguously implies trend stationarity. Lee and Strazicich (2003) [13] considered model A which allows for two changes in the level and Model $\mathrm{C}$ which allows for two changes in level and trend. Model B was excluded as most economic time series can be modelled using models A and C.

Using the notation of Lee and Strazicich (2003) [13], the DGP (Data Generating Process) is considered as follows:

$$
y_{t}=\delta^{\prime} Z_{t}+e_{t}, \quad e_{t}=\beta e_{t-1}+\varepsilon_{t}, \quad \varepsilon_{t} \sim \operatorname{iidN}\left(0, \sigma^{2}\right)
$$

where $Z_{t}$ is a vector of exogenous variables, $\delta$ is a vector of parameters, $\varepsilon_{t}$ is error term with classical properties.

In model A, $Z_{t}=\left[1, t, D_{1 t}, D_{2 t}\right]$, and $\delta=\left[\mu, \gamma, d_{1}, d_{2}\right]$.

In model $\mathrm{C}$ that allows for two endogenous breaks in the level and trend, $Z_{t}=\left[1, t, D_{1 t}, D_{2 t}, D T_{1 t}, D T_{2 t}\right]$, and $\delta=$ $\left[\mu, \gamma, d_{1}, d_{2}, d_{3}, d_{4}\right]$, Where $D_{j t}$ and $D T_{j t}$ for $j=1,2$ are two dummies defined as:

$$
\begin{aligned}
& D_{j t}=\left\{\begin{array}{ll}
1 & t \geq T B_{j}+1 \\
0 & \text { otherwise }
\end{array}, \quad j=1,2,\right. \\
& D T_{j t}=\left\{\begin{array}{ll}
t-T B_{j} & t \geq T B_{j}+1 \\
0 & \text { otherwise }
\end{array}, \quad j=1,2,\right.
\end{aligned}
$$

where $T B_{j}$ denotes the break date (the time period when a break occurs). The null and alternative hypotheses for model A are given by:

Null hypothesis: $y_{t}=\mu_{0}+d_{1} B_{1 t}+d_{2} B_{2 t}+y_{t-1}+v_{1 t}$ 
Alternative hypothesis: $y_{t}=\mu_{1}+\gamma t+d_{1} D_{1 t}+d_{2} D_{2 t}+v_{2 t}$

For model $\mathrm{C}$, the null and alternative hypotheses are given by:

Null hypothesis: $y_{t}=\mu_{0}+d_{1} B_{1 t}+d_{2} B_{2 t}+d_{3} D_{1 t}+d_{4} D_{2 t}+y_{t-1}+v_{1 t}$

Alternative hypothesis: $y_{t}=\mu_{1}+\gamma t+d_{1} D_{1 t}+d_{2} D_{2 t}+d_{3} D T_{1 t}+d_{4} D T_{2 t}+v_{2 t}$

where $v_{1 t}$ and $v_{2 t}$ are stationary error terms.

$B_{j t}=\left\{\begin{array}{cc}1 & t=T B_{j}+1 \\ 0 & \text { otherwise }\end{array}, \quad j=1,2\right.$,

The two-break LM unit root test statistic is obtained from the following regression:

$$
\Delta y_{t}=\delta^{\prime} \Delta Z_{t}+\phi \tilde{S}_{t-1}+u_{t}
$$

where $\tilde{S}_{t}=y_{t}-\tilde{\psi}_{x}-Z_{t} \tilde{\delta}, t=2, \ldots, T ; \tilde{\delta}$ are coefficients in the regression of $\Delta y_{t}$ on $\Delta Z_{t} ; \tilde{\psi}_{x}$ is given by $y_{1}-Z_{1} \tilde{\delta}$; and $y_{1}$ and $Z_{1}$ denote the first observation of $y_{t}$ and $Z_{t}$, respectively. The unit root null hypothesis is given by: $\phi=0$. The LM test statistics are given by: $\tilde{\rho}=T \tilde{\phi}$, where $T$ is the sample size. The $t$-statistic $\tilde{\tau}$ is used to test the null hypothesis $\phi=0$. The break dates are estimated using a grid search method as follows:

$$
\begin{aligned}
& \mathrm{LM}_{\rho}=\inf _{\lambda} \tilde{\rho}(\lambda) \\
& \mathrm{LM}_{\tau}=\inf _{\lambda} \tilde{\tau}(\lambda)
\end{aligned}
$$

where $\lambda=\left(\lambda_{1}=\frac{T B_{1}}{T}, \lambda_{2}=\frac{T B_{2}}{T}\right), \lambda \in(0,1)$ is the proportion of observations occurring prior to the break, $T$ is the sample size (total number of observations), ${ }^{*}$ and $T B_{j}=\left[\lambda_{j} T\right], j=1,2,[$.$] : is greatest integer function. In order to eliminate end$ points, the grid search is undertaken over the trimming region [.10T, .90T] to determine the break dates (TB).

As a benchmark exercise, we first tested the unit root hypothesis without structural breaks using the conventional ADF, PP and KPSS tests. Then we tested the unit root with structural breaks using the Lagrange multiplier (LM) test of [13]. The following flowchart describes the econometric methodology used in the study.

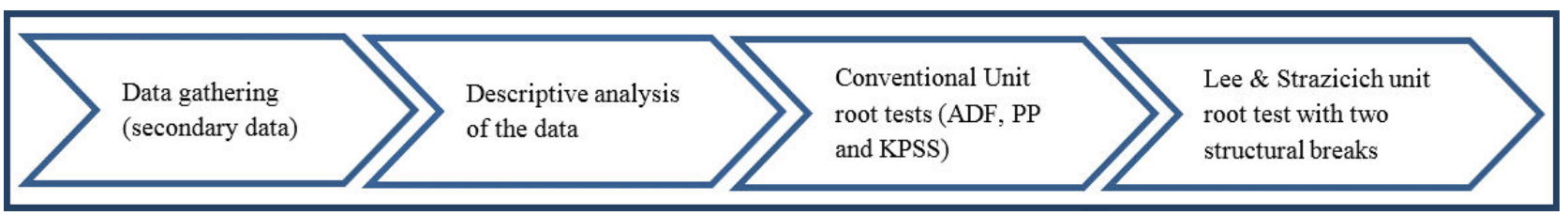

Figure 1. Flowchart of the research methodology.

\section{3-2-Data}

We use annual data of petroleum products consumption, measured in thousands metric tons, reported in the annual reports of the Jordan Ministry of Energy and Mineral Resources and the Jordan Petroleum Refinery Company (JPRC) over the period 1961-2020. The petroleum products include (liquefied petroleum gas, gasoline, jet fuel, kerosene, diesel, fuel oil and asphalt). Following [1, 22, 23], the data was converted into natural logarithm. Figure 2 shows the evolution of petroleum products consumption and Table 1 shows the summary statistics for petroleum products consumption.

Table 1. Descriptive statistics of annual petroleum products consumption (measured in thousands metric tons).

\begin{tabular}{cccccccc}
\hline Series & Observations & Mean & Stad. Dev. & Min. & Max. & Skewness & Kurtosis \\
\hline Petroleum products consumption & 59 & 3028.637 & 2017.324 & 236.506 & 7420.133 & 0.082 & 1.913 \\
\hline
\end{tabular}

\footnotetext{
${ }^{*}$ Perron (1989) called $\lambda$ the break fraction.
} 


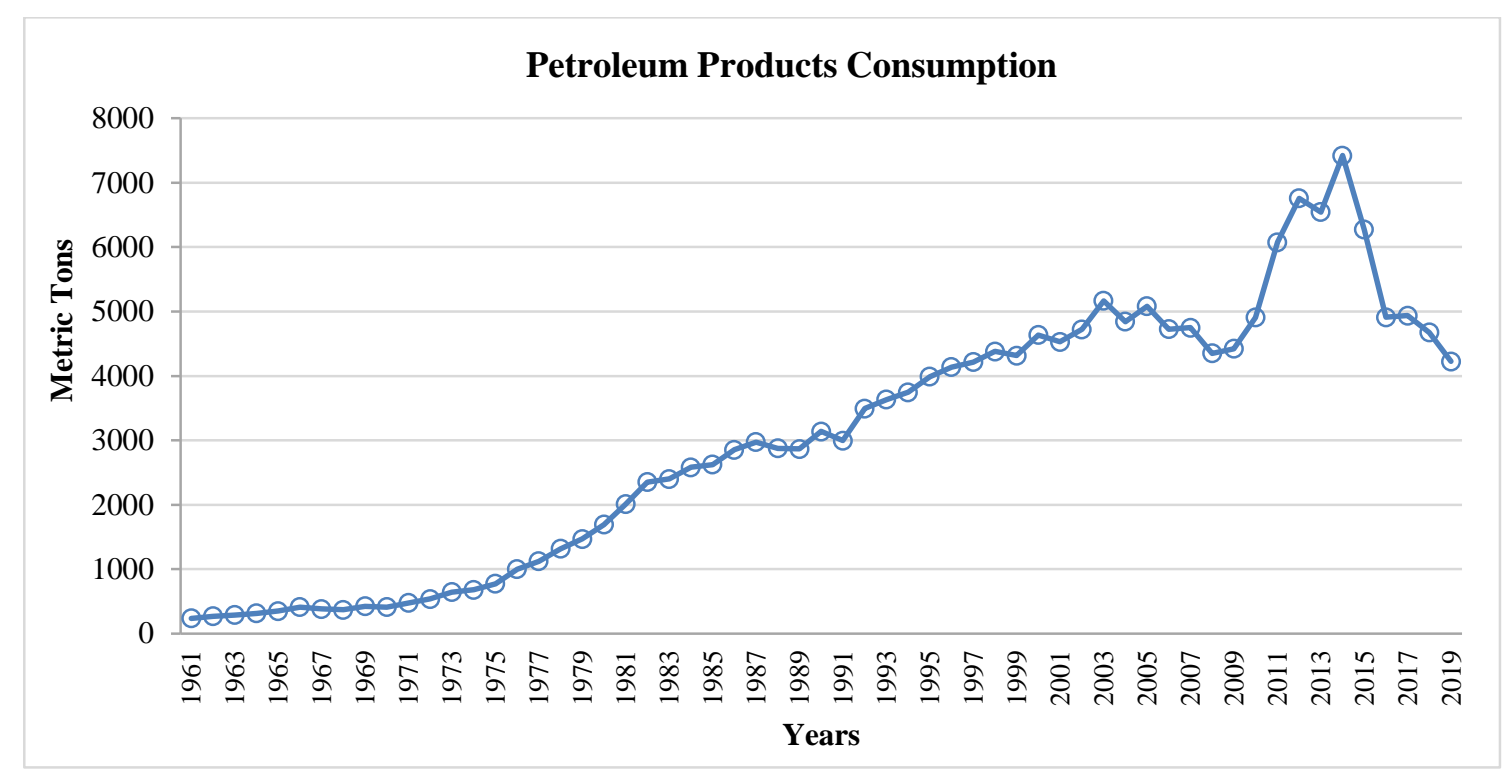

Figure 2. The evolution of petroleum products consumption (1961-2019).

\section{4- Results}

Following the tradition in the literature, we apply the conventional unit root and stationarity tests without structural breaks in order to have a benchmark against which other unit roots can be compared with. In particular, the ADF and Phillips Perron (PP) were used to test for unit root, and the KPSS was used to test for stationarity, with and without a trend. As shown in Table 2, with intercept, both ADF and PP tests reject the unit root null, and KPSS rejects the null of stationarity. With intercept and trend, ADF and PP suggest that both series have unit root, while KPSS does not reject the stationarity null for the consumption series. Therefore, no decisive conclusion can be reached based on conventional unit root tests without breaks.

Table 2. Results of traditional unit root tests.

\begin{tabular}{ccccccc}
\hline Series & \multicolumn{2}{c}{ Intercept } & \multicolumn{3}{c}{ Trend and Intercept } \\
\hline & ADF test & PP test & KPSS test & ADF test & PP test & KPSS test \\
\hline Consumption & $-3.440 * * *$ & $-2.836^{*}$ & $0.849 * * *$ & 0.400 & 0.061 & 0.238 \\
\hline$* \& * * *$ denote significance at $10 \% \& 1 \%$, respectively. & & & &
\end{tabular}

To overcome those problems associated with the conventional unit root and stationarity tests discussed above, we apply [13] unit root test with breakpoints in intercept (Model A or Crash model) and in intercept and slope (Model C or Break model). As shown in Table 3, the test fails to reject the null of unit root with breaks of both models. This suggests that petroleum products consumption series contains unit root. This result has several implications. First, shocks to petroleum products consumption are expected to have permanent effects. Second, it is expected that the impacts of those shocks will be transmitted to other sectors of the economy, especially those that are highly related to energy sector. Finally, because the series contains unit root, the attempts to forecast future consumption are not accurate, at least for the timeframe in this study.

Table 3. Results of Lee and Strazicich (2003) unit root test with two structural breaks (Model A and Model C).

\begin{tabular}{ccccccc}
\hline Series & \multicolumn{2}{c}{ Model A (Crash): Break in Intercept } & \multicolumn{3}{c}{ Model C (Break): Break in Intercept and trend } \\
\hline & Test statistic & TB1 & TB2 & Test statistic & TB1 & TB2 \\
\hline Consumption & -2.601 & 1971 & 2007 & -5.490 & 1979 & 2007 \\
\hline
\end{tabular}

Note: TB1 and TB2 refer to the time of the breaks

\section{5- Conclusion and Policy Implications}

In response to the calls of Smyth \& Narayan (2015), Smyth (2013) and Lean \& Smyth (2013) [5-7] to conduct research in countries other than the United States in order to increase the knowledge of unit root properties of energy variables in other countries, this study intends to fill in a significant gap in the literature of applied energy that is related to testing the stationarity properties of petroleum products consumption in Jordan over the period 1961 to 2019 . To achieve the goal of the study, we applied each of the ADF, PP and KPSS tests twice: once with intercept and once with 
intercept and trend. However, the results concerning the existence of unit root were inconclusive. Therefore, the Lee and Strazicich (2003) [13] test was used to compromise the conflicting results of the traditional unit root and stationarity tests without breaks. The empirical findings of Lee and Strazicich (2003) [13] test confirm that the consumption series is a unit root process (i.e., non-stationary). Based on these findings a number of policy implications emerge. First, shocks to petroleum products consumption are expected to have permanent effects. Second, it is expected that the impacts of those shocks will be transmitted to other sectors of the economy, especially those that are highly related to energy sector. In view of that, the government's efforts to reduce the consumption of fossil oils and to increase the usage of renewable energy are expected to have long run impacts. Finally, because the series contains unit root, the attempts to forecast future consumption are not accurate, at least for the timeframe in this study.

As mentioned earlier, this is the first attempt to study the stationarity properties of one of the energy variables in Jordan and it is intended to be a benchmark against which future research can be compared with. Therefore, a wide array of future research can be undertaken including, but not limited to, testing stationarity of other energy variables including electricity and renewable energy

\section{6- Declarations}

\section{6-1-Author Contributions}

All authors contributed to the design and implementation of the research, to the analysis of the results, and to the writing of the manuscript. All authors have read and agreed to the published version of the manuscript.

\section{6-2-Data Availability Statement}

The data presented in this study are available on request from the corresponding author.

\section{6-3- Funding}

The authors received no financial support for the research, authorship, and/or publication of this article.

\section{6-4- Conflicts of Interest}

The authors declare that there is no conflict of interests regarding the publication of this manuscript. In addition, the ethical issues, including plagiarism, informed consent, misconduct, data fabrication and/or falsification, double publication and/or submission, and redundancies have been completely observed by the authors.

\section{7- References}

[1] Apergis, Nicholas, and James E. Payne. "Structural Breaks and Petroleum Consumption in US States: Are Shocks Transitory or Permanent?” Energy Policy 38, no. 10 (October 2010): 6375-6378. doi:10.1016/j.enpol.2010.06.015.

[2] Solarin, Sakiru Adebola, and Hooi Hooi Lean. "Are Fluctuations in Oil Consumption Permanent or Transitory? Evidence from Linear and Nonlinear Unit Root Tests.” Energy Policy 88 (January 2016): 262-270. doi:10.1016/j.enpol.2015.10.034.

[3] Ozcan, Burcu. "Are Shocks to Energy Consumption Permanent or Temporary? The Case of 17 Middle East Countries.” Energy Exploration \& Exploitation 31, no. 4 (August 2013): 589-605. doi:10.1260/0144-5987.31.4.589.

[4] Ibrahim, Mustapha D., and Andrew Adewale Alola. "Integrated Analysis of Energy-Economic Development-Environmental Sustainability Nexus: Case Study of MENA Countries." Science of the Total Environment 737 (October 2020): 139768. doi:10.1016/j.scitotenv.2020.139768.

[5] Smyth, Russell, and Paresh Kumar Narayan. “Applied Econometrics and Implications for Energy Economics Research.” Energy Economics 50 (July 2015): 351-358. doi:10.1016/j.eneco.2014.07.023.

[6] Smyth, Russell. "Are Fluctuations in Energy Variables Permanent or Transitory? A Survey of the Literature on the Integration Properties of Energy Consumption and Production." Applied Energy 104 (April 2013): 371-378. doi:10.1016/j.apenergy.2012.10.069.

[7] Lean, Hooi Hooi, and Russell Smyth. "Are Shocks to Disaggregated Energy Consumption in Malaysia Permanent or Temporary? Evidence from LM Unit Root Tests with Structural Breaks.” Renewable and Sustainable Energy Reviews 31 (March 2014): 319 328. doi:10.1016/j.rser.2013.10.040.

[8] Ozturk, Ilhan, and Alper Aslan. “Are Fluctuations in Energy Consumption Per Capita Transitory? Evidence from Turkey.” Energy Exploration \& Exploitation 29, no. 2 (June 2011): 161-167. doi:10.1260/0144-5987.29.2.161.

[9] Warrad, Taleb M. Awad, and Sameh A. Ajlouni. "Is Jordan Petroleum Refinery Company a Natural Monopoly?." Journal of Applied Economics \& Business Research 2, no. 4 (2012).

[10] Kwiatkowski, Denis, Peter C.B. Phillips, Peter Schmidt, and Yongcheol Shin. "Testing the Null Hypothesis of Stationarity against the Alternative of a Unit Root.” Journal of Econometrics 54, no. 1-3 (October 1992): 159-178. doi:10.1016/03044076(92)90104-y. 
[11] Dickey, David A., and Wayne A. Fuller. "Distribution of the Estimators for Autoregressive Time Series with a Unit Root." Journal of the American Statistical Association 74, no. 366 (June 1979): 427-431. doi:10.2307/2286348.

[12] Perron, Pierre. "The Great Crash, the Oil Price Shock, and the Unit Root Hypothesis." Econometrica 57, no. 6 (November 1989): 1361-1401. doi:10.2307/1913712.

[13] Lee, Junsoo, and Mark C. Strazicich. "Minimum Lagrange Multiplier Unit Root Test with Two Structural Breaks." Review of Economics and Statistics 85, no. 4 (November 2003): 1082-1089. doi:10.1162/003465303772815961.

[14] Kumar Narayan, Paresh, and Russell Smyth. “Are Shocks to Energy Consumption Permanent or Temporary? Evidence from 182 Countries.” Energy Policy 35, no. 1 (January 2007): 333-341. doi:10.1016/j.enpol.2005.11.027.

[15] Kumar Narayan, Paresh, Seema Narayan, and Stephan Popp. "Energy Consumption at the State Level: The Unit Root Null Hypothesis from Australia.” Applied Energy 87, no. 6 (June 2010): 1953-1962. doi:10.1016/j.apenergy.2009.10.022.

[16] Aslan, Alper, and Hakan Kum. "The Stationary of Energy Consumption for Turkish Disaggregate Data by Employing Linear and Nonlinear Unit Root Tests.” Energy 36, no. 7 (July 2011): 4256-4258. doi:10.1016/j.energy.2011.04.018.

[17] Zivot, Eric, and Donald W. K. Andrews. "Further Evidence on the Great Crash, the Oil-Price Shock, and the Unit-Root Hypothesis.” Journal of Business \& Economic Statistics 10, no. 3 (July 1992): 251. doi:10.2307/1391541.

[18] Lumsdaine, Robin L., and David H. Papell. "Multiple Trend Breaks and the Unit-Root Hypothesis." Review of Economics and Statistics 79, no. 2 (May 1997): 212-218. doi:10.1162/003465397556791.

[19] Lee, Junsoo, and Mark C. Strazicich. "Minimum LM unit root test with one structural break." Manuscript, Department of Economics, Appalachian State University 33, no. 4 (2004): 2483-2492.

[20] Lee, Junsoo, and Mark C. Strazicich. "Minimum LM unit root test with one structural break." Economics bulletin, 33, no. 4 (2013): 2483-2492.

[21] Narayan, Paresh Kumar, and Stephan Popp. “A New Unit Root Test with Two Structural Breaks in Level and Slope at Unknown Time.” Journal of Applied Statistics 37, no. 9 (September 2010): 1425-1438. doi:10.1080/02664760903039883.

[22] Mishra, Vinod, and Russell Smyth. "Is Monthly US Natural Gas Consumption Stationary? New Evidence from a GARCH Unit Root Test with Structural Breaks.” Energy Policy 69 (June 2014): 258-262. doi:10.1016/j.enpol.2014.03.033.

[23] Mishra, Vinod, and Russell Smyth. "Unit root properties of natural gas spot and futures prices: The relevance of heteroskedasticity in high frequency data.” Monash University., Department of Economics, (2014).

[24] Destek, Mehmet Akif, and Samuel Asumadu Sarkodie. "Are Fluctuations in Coal, Oil and Natural Gas Consumption Permanent or Transitory? Evidence from OECD Countries.” Heliyon 6, no. 2 (February 2020): e03391. doi:10.1016/j.heliyon.2020.e03391.

[25] Demir, Ender, and Giray Gozgor. "Are Shocks to Renewable Energy Consumption Permanent or Temporary? Evidence from 54 Developing and Developed Countries." Environmental Science and Pollution Research 25, no. 4 (November 24, 2017): 37853792. doi:10.1007/s11356-017-0801-9.

[26] Akram, Vaseem, Pradipta Kumar Sahoo, and Bhushan Praveen Jangam. "Do Shocks to Electricity Consumption Revert to Its Equilibrium? Evidence from Indian States.” Utilities Policy 61 (December 2019): 100977. doi:10.1016/j.jup.2019.100977.

[27] Aydin, Mucahit, and Ugur Korkut Pata. "Are Shocks to Disaggregated Renewable Energy Consumption Permanent or Temporary for the USA? Wavelet Based Unit Root Test with Smooth Structural Shifts.” Energy 207 (September 2020): 118245. doi:10.1016/j.energy.2020.118245.

[28] Lee, Chien-Chiang, Omid Ranjbar, and Chi-Chuan Lee. "Analyzing the Hysteresis Properties and Growth Stability of Renewable Energy Production of the U.S.” Applied Economics 53, no. 24 (January 24, 2021): 2752-2770. doi:10.1080/00036846.2020.1869168.

[29] Lee, Chien-Chiang, Omid Ranjbar, and Chi-Chuan Lee. "Testing the Persistence of Shocks on Renewable Energy Consumption: Evidence from a Quantile Unit-Root Test with Smooth Breaks.” Energy 215 (January 2021): 119190. doi:10.1016/j.energy.2020.119190. 